\title{
The gasifier temperature control design based on the fuzzy PID control Cheng Peng
}

\author{
North China Electric Power University, Baoding 071000, China
}

Keywords: biomass gasification process, Fuzzy - PID control.

\begin{abstract}
In view of the biomass gasification processes a nonlinear, non-minimum phase characteristics, instability, dynamic process of the characteristics of the large delay and load disturbance, contains a large number of uncertainty factors, accurate mathematical model is hard to express, using a single control algorithm design of general control system is difficult to achieve the desired effect, and puts forward the Fuzzy - PID Fuzzy control technology combined with conventional PID control algorithm, achieve better control of temperature in gasifier furnace.
\end{abstract}

\section{Gasifier furnace temperature control system}

In biomass gasifier, the main factors influencing the temperature changes in the furnace ${ }^{[1]}$ are: (1) the change of the biomass of quantification ally; (2) the air volume change at a time. Control the two quantities that can control the temperature of the gasifier, establishes on the furnace temperature control system is shown in figure 1.

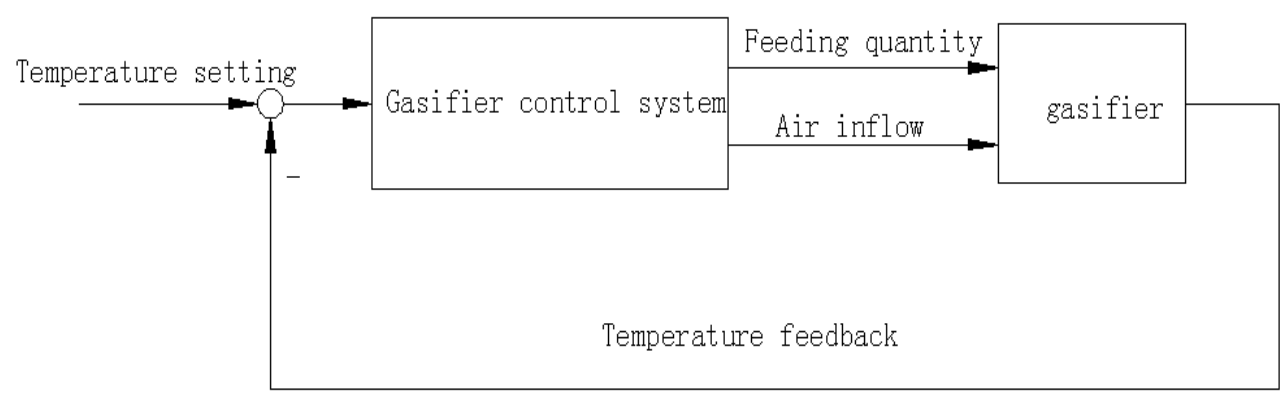

Fig. 1 temperature control system diagram

\section{PID control principle}

PID controller according to the characteristics of the controlled object, of the three parameters setting, in order to obtain satisfactory control effect.From the system stability and response speed, overshoot and steady precision and so on various aspects to consider, the role of KP, KI, KD is as follows:

(1) Proportional coefficient KP can speed up the system response speed, improve the adjustment precision of the system.

(2) The integral coefficient KI can eliminate the system steady-state error.

(3) Differential coefficient KD can improve the dynamic characteristics of system, inhibit the response of deviation in the process of change.

\section{The design of Fuzzy- PID controller}

\subsection{The fuzzy treatment}

Input deviation e, ec deviation change blurred fuzzy controller input and output variables are acc urate quantity, fuzzy inference was conducted in view of the fuzzy quantity,therefore, the controller must first to blur the input.In this project were to design a Fuzzy - PID controller, for Fuzzy PID, it has two input, with the field for a given error e and error change rate of ec, the theory of quantitativ e domain for [3, 3], a total of seven Fuzzy language variables, respectively, NB, NM, NS, Z0, PS, P 
$\mathrm{M}$ and $\mathrm{PB}$, membership functions with strong sensitivity of trigonometric function. Membership fun ction is shown in figure 2 . The output of the delta $\mathrm{P}$ quantitative theory of domain for [3, 3], delta $\mathrm{d}$ omain of quantitative theory I to [0.6, 0.6], AD the quantitative theory of domain for [3, 3], $\Delta \mathrm{P}$ and $\Delta \mathrm{D}$ membership function is the same as the input's, $\Delta \mathrm{I}$ membership functions as shown in figure $3^{[2]}$.

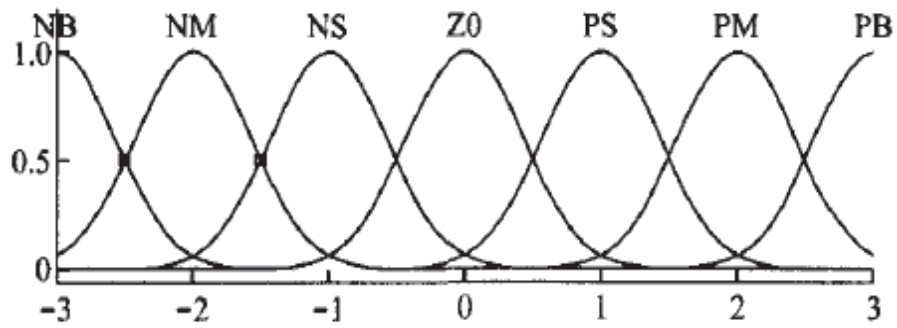

Fig. 2 Membership function of input

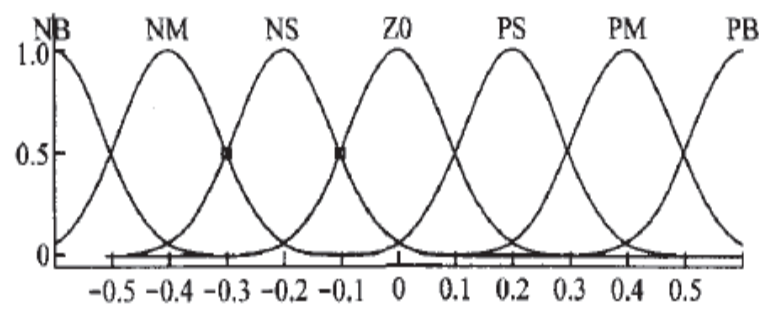

Fig. 3 Membership function of $\Delta \mathrm{I}$

\subsection{Parameter setting rules and fuzzy reasoning}

Fuzzy control rules is to $\Delta \mathrm{P}, \Delta \mathrm{I}, \Delta \mathrm{D}$ parameters adjustment rules. Parameter setting principle is the core of the controller, it is the summary of the operator and the expert's experience knowledge. Induces the $\Delta \mathrm{P}, \Delta \mathrm{I}$ and $\Delta \mathrm{D}$ fuzzy rules are shown in table 1 to table $3^{[3]}$.

Tab. 1 Fuzzy control rules of $\Delta \mathrm{P}$

\begin{tabular}{|c|c|c|c|c|c|c|c|c|}
\hline \multirow{2}{*}{\multicolumn{2}{|c|}{$\Delta P$}} & \multicolumn{7}{|c|}{$e c$} \\
\hline & & NB & NM & NS & $\mathrm{ZO}$ & PS & $\mathrm{PM}$ & $\mathrm{PB}$ \\
\hline \multirow{7}{*}{$e$} & NB & $\mathrm{PB}$ & $\mathrm{PB}$ & PM & PM & PS & Zo & ZO \\
\hline & NM & $\mathrm{PB}$ & $\mathrm{PB}$ & PM & PS & PS & $\mathrm{ZO}$ & NS \\
\hline & NS & $\mathrm{PM}$ & $\mathrm{PM}$ & $\mathrm{PM}$ & PS & $\mathrm{ZO}$ & NS & NS \\
\hline & Zo & PM & $\mathrm{PM}$ & PS & Zo & NS & NM & $\mathrm{NM}$ \\
\hline & PS & PS & PS & Z0 & NS & NS & NM & $\mathrm{NM}$ \\
\hline & PM & PS & Zo & NS & $\mathrm{NM}$ & NM & NM & NB \\
\hline & PB & Zo & Zo & $\mathrm{NM}$ & NM & NM & $\mathrm{NB}$ & NB \\
\hline
\end{tabular}

Tab. 2 Fuzzy control rules of $\Delta \mathrm{I}$ 


\begin{tabular}{|c|c|c|c|c|c|c|c|c|}
\hline & \multirow{2}{*}{$\Delta I$} & \multicolumn{7}{|c|}{$e c$} \\
\hline & & NB & NM & NS & 20 & PS & $\mathrm{PM}$ & PB \\
\hline \multirow{7}{*}{$e$} & NB & NB & NB & $\mathrm{NM}$ & NM & NS & $\mathrm{ZO}$ & Zo \\
\hline & $\mathrm{NM}$ & $\mathrm{NB}$ & $\mathrm{NB}$ & NM & NS & NS & $Z_{0}$ & Zo \\
\hline & NS & NB & NM & NS & NS & Zo & PS & PS \\
\hline & $\mathrm{Z} 0$ & NM & $\mathrm{NM}$ & NS & Z0 & PS & $\mathrm{PM}$ & PM \\
\hline & PS & NM & NS & $\mathrm{Z} 0$ & PS & PS & $\mathrm{PM}$ & $\mathrm{PB}$ \\
\hline & PM & Zo & Zo & PS & $\mathrm{PM}$ & $\mathrm{PB}$ & PB & $\mathrm{PB}$ \\
\hline & PB & Z0 & $\mathrm{Z}_{0}$ & NM & PS & $\mathrm{PM}$ & PB & PB \\
\hline
\end{tabular}

Tab. 3 Fuzzy control rules of $\Delta \mathrm{D}$

\begin{tabular}{|c|c|c|c|c|c|c|c|c|}
\hline & \multirow{2}{*}{$\Delta D$} & \multicolumn{7}{|c|}{$e c$} \\
\hline & & NB & NM & NS & $Z_{0}$ & PS & PM & PB \\
\hline \multirow{7}{*}{$e$} & NB & PS & NS & NB & $\mathrm{NB}$ & $\mathrm{NB}$ & NM & PS \\
\hline & NM & PS & NS & NB & NM & NM & NS & $\mathrm{ZO}$ \\
\hline & NS & $\mathrm{ZO}$ & NS & $\mathrm{NM}$ & NM & NS & NS & 20 \\
\hline & Zo & $\mathrm{Z} 0$ & NS & NS & NS & NS & NS & Zo \\
\hline & PS & $\mathrm{ZO}$ & Zo & Z0 & Zo & $\mathrm{ZO}$ & $\mathrm{Z}_{0}$ & $\mathrm{Z} 0$ \\
\hline & $\mathrm{PM}$ & $\mathrm{PB}$ & NS & PS & PS & PS & PS & PB \\
\hline & PB & PB & PM & PM & PS & PS & PS & PB \\
\hline
\end{tabular}

\subsection{The center of gravity method for defuzzification}

After the above Fuzzy reasoning, Fuzzy - PID controller setting three correction to blur parameter to obtain accurate quantity to calculate the output control amount. This controller, the use of the precision of the gravity method to calculate the output value, the input to the PID controller parameters calculated by the following formula:

$$
\begin{aligned}
& K_{P}=K_{P 0}+\Delta K_{P} \\
& K_{I}=K_{I 0}+\Delta K_{I} \\
& K_{D}=K_{D 0}+\Delta K_{D}
\end{aligned}
$$

\section{The simulation}

Based on the biomass gasifier furnace temperature control system as an example, carry on the si mulation experiment.To illustrate the effectiveness of the proposed method, the method of PID cont rol and the method for the simulation.Figure 4 for the system unit step response curve of the two me thods.

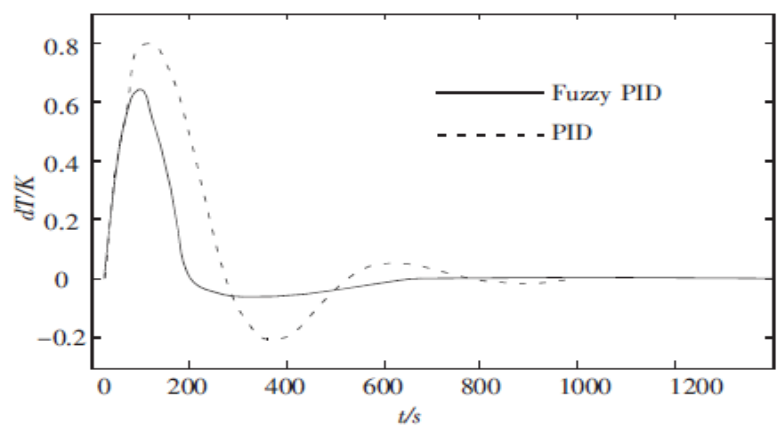

Figure 4. The gasifier temperature control system response contrast figure 
Can be seen from the above closed-loop response process, two kinds of control mode to achieve the goal of the temperature control, but by contrast, found that the fuzzy PID control system makes the transition of the system output response time is short, good tracking performance and improve the control precision of fuzzy PID control method is superior to the conventional PID control method.

\section{References}

[1] Wang Zhongxian, zhang hong, Chen Xing yuan, etc. Simulation and experiment of heat pipe biomass gasifier [J]. Journal of Jiangsu university: natural science edition, 2008, 29 (6): 512-515.

[2] Rocky. Based on fuzzy control theory is a kind of PID parameters self-tuning controller design and simulation. Automation and instrumentation, 2000, No.

[3] chun-hua wang, zhao-ping zhong, Hubei strengthened. Biomass gasifier of intelligent control based on fuzzy neural network [J]. Journal of power engineering, 2009, 29 (9): 327-330. 